\title{
Numerical and Mechanical Modeling of Reciprocating Type of Wind Harvester for Rural and Remote Areas to Generate Electrical Power
}

\author{
Halefom Kidane ${ }^{1^{*}} \quad$ Gebremeskel Tekle ${ }^{2}$ \\ 1.Hawassa university Institute of Technology, Depart of Mechanical Engineering \\ 2.AdiGrat University, College of Natural and Computational Science, Department of Physics
}

\begin{abstract}
Now day's energy is the fourth basic needs for human beings after food, cloth and shelter. On the other hand energy has also its own draw back to our living environment especially if we are using fossil fuels as source of energy. Wind energy is among the recently flourishing technologies and get more acceptance from time to time to meet the energy demand of the societies and to reduce the environmental crises happen due to fossil fuels. Thus, Small wind turbines are the best options to provide power for those which have limited power access and areas far from the central grid. Areas which have a lot wild diversity especially birds reciprocating type of small wind turbines are good alternative to save the life of the birds. Designing a reciprocation type wind power harvester which is able to produce electricity with low cost, designing analysis, manufacturing and maintenance was the main objectives of the work. The overall procedure for completing the project starts by collecting relevant data for the design up to finalizing the project as a methodology. The Core parties were designed and suitable material by considering different criteria were selected for individual components. The design made ware safe and turbine is economically feasible and environmentally friendly. Finally, this technical document concluded that the capacity of the Reciprocating Type Wind Power Harvester produces the ideal output power of $10.125 \mathrm{kw}$ at the tower high of $20 \mathrm{~m}$ above the ground with cut in speed of $3 \mathrm{~m} / \mathrm{s}$ wind speed
\end{abstract}

Keywords: Energy, Wind energy, reciprocating type, small wind turbine

DOI: $10.7176 / \mathrm{JETP} / 10-3-01$

Publication date:July $31^{\text {st }} 2020$

\section{INTRODUCTION}

The benefit of energy is clear for everyone no matter its profession he or she is. We use energy to cook and baking our daily food, to entertain(to listing music to watch tv etc. ), to transport from place to place(using cars, motor cycles, airplane etc.),to run our industries, to keep our personal comfort using (ventilators, heaters and different air conditioning systems), to communicate with peoples ,to iron our clothes etc. So, no one can argue us we can say that energy the fourth basic needs for human beings' after food, cloth and shelter.

This energy comes from different source like fossil fuels (oil, natural gas, coal), renewable energies (Hydropower, wind, solar, tidal, geothermal etc.).

In our country Ethiopia Hydro power sources will remain the most important electrical energy sources for the country, however this source of power is just limited ln urban and semi urban areas only. However, about $85 \%$ of the total population of the country are living in rural areas. From this huge number only few of the rural population have access to the electricity from grid. This is because of scattered way of settlement; difficult geographical landscape and low population density of the communities providing grid electricity for the rural population of Ethiopia require huge budgets for its implementation. So, to overcome such problems small scale wind turbines are the best alternatives to expand electricity to society. However, the current turbines which are available in the market are very expensive to buy, expensive to build, difficult access to repair, difficult for ecosystem, they are so noisy etc. such type of draw backs can be avoided by using the new concept design which is called reciprocating type of wind turbine is introducing here.

\section{METHODOLOGY}

\subsection{General Frame Work of Study}

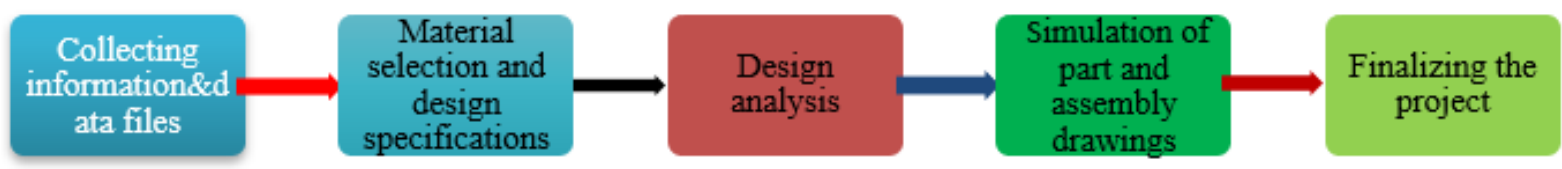

Figure 2: General procedure of the research

\subsection{Data Collection}

The relevant information about wind speed and wind variations depend on the altitude of wind vane are collected. 
Thus, relevant data were taken from South Nations Nationalities and Regional of peoples of Ethiopia (SNNPR) Metrological agency which is located in Hawassa. The data that we take from Metrological Station at Hawassa for the successive four years of (2017-2018) about wind speed and wind variations are the basic of this project to start the design analysis.

\subsection{Material selection}

The factors which should were considered while we select the material for the machine component are availability, low cost, mechanical properties, ease of handling, ease of use, environment friendly, portability, low noise, ease of maintainable etc.

\section{RESULT, DISCUSSION AND CONCEPT DEVELOPMENT OF THE PROJECT}

Here under this title the core parts of the harvester were designed and different materials and numerical were taken from standard. The average wind speed of the site for the year 2017 and 2018 of the selected site varies between $3.5 \mathrm{~m} / \mathrm{s}$ and $6.5 \mathrm{~m} / \mathrm{s}$. So, in this project for simplicity we have took average wind speed as $5 \mathrm{~m} / \mathrm{s}$.

\subsection{Design of main parts of Reciprocating Type Wind Power Harvester}

There are different kind forces which can be considered in the design of wind turbine blade. The most commons are Stochastic loads, Cyclic loads, Steady (Static and rotating), resonance-induced loads [1-10]

\subsubsection{Design of Rectangular Plate (Blade)}

The plate is a place in which the wind strikes and the power of wind is absorbed. The plate is not fixed or rigid instead as we see from the figure 3 below it has three modules which is connected to the frame by freely pin connection. This rectangular blade has reciprocating motion i.e. forward and backward motion. In the forward direction the modules are closed so the wind power absorbed and stored on the flywheel. Due to the power stored on the flywheel the rectangular blade returns to original position and in this backward direction the modules are opened so the wind by pass the module. The opening and closing of modules are controlled by cylindrical cam mechanism. This cam mechanism helps to rotates only the central module therefore we use rod which helps to turn the sides module because the rod connects the modules include the central one.

N.B all the design formulas which are used were taken from reference [2 and 3].

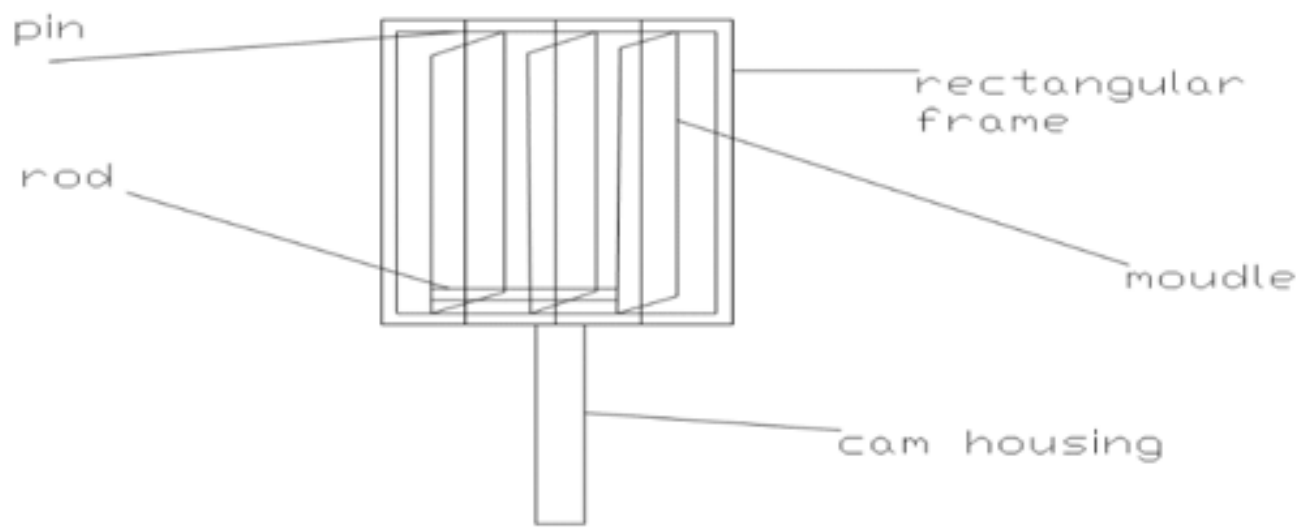

Figure 3: Rectangular Plate with Frame

\subsubsection{Design of Module on Rectangular Blade}

There are three identical modules on the rectangular blade with the same material, the same dimension and they have same pressure distribution. So, we can consider the single plate for design

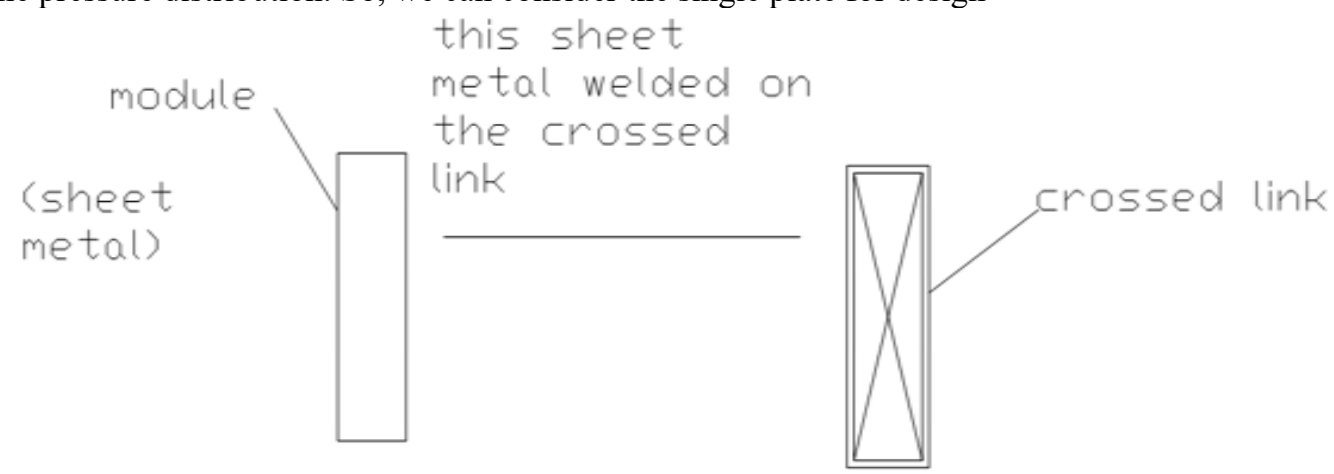

Figure 4: Module (Plate) 
Now let us take, the dimension of the module (sheet metal)

$\operatorname{Height}(\mathrm{H})=2.5 \mathrm{~m}, \mathrm{Width}(\mathrm{w})=0.67 \mathrm{~m}$

The cross section of link is $20 \mathrm{~mm} * 20 \mathrm{~mm}$ and it is hollow square with thickness of 1.5 .

\subsubsection{The Stress Analysis on The Module}

As we see from figure 4 above the thin sheet metal welded on the link (instead of use think sheet metal) which experience bending stress due to wind power. And this structure helps to reduce the weight of rectangular blade and cost. Find stress on link means find stress on module this stress is bending stress. The design or selection of material is based on central link (i.e. the inclined one) because there is high binding stress induce on it. The length of inclined link is

$\mathrm{L}=\sqrt{2.5^{2}+0.67^{2}}=2.59 \mathrm{~m}, \mathrm{w} \times \mathrm{b}=20 \mathrm{~mm} \times 20 \mathrm{~mm}$ and hollow square, $\mathrm{t}=1.5 \mathrm{~mm}$

The area of the link which is perpendicular to the wind force in $\mathrm{mm}$ is

$$
\mathrm{A}=\mathrm{L} \times \mathrm{W}=2590 \mathrm{~mm} \times 20 \mathrm{~mm}=51,800 \mathrm{~mm}^{2}
$$

The force exerted by wind on the link at center is

$$
\mathrm{F}=\mathrm{P} \times \mathrm{A}=135^{N} / \mathrm{m}^{2} \times 0.0518 \mathrm{~m}^{2}=6.993 \mathrm{~N}
$$

The maximum bending moment on the link is at the center

$\mathrm{M}_{\text {max }}=\frac{\mathrm{W} \times \mathrm{L}}{4}=\frac{6.993 \times 2590}{4}=4527.97 \mathrm{Nmm}$

Section modulus $(Z)$ of this hollow square is

$$
\begin{aligned}
& Z=\frac{b^{4}-h^{4}}{6 b} \quad \text { but, } \mathrm{h}=\mathrm{b}-2 \mathrm{t}=20-(2 \times 1.5)=\underline{\underline{17 \mathrm{~mm}}} \\
& Z=\frac{20^{4}-17^{4}}{6 \times 20}=\underline{\underline{637.325 \mathrm{~mm}^{4}}}
\end{aligned}
$$

We know that binding stress $\left(\sigma_{b}\right)$ is

$\sigma_{b}=\frac{M_{\max }}{Z}=\frac{4527.97}{637.325}=7.1 \mathrm{~N} / \mathrm{mm}^{2}$

We take the Factor of safety (Fos) $=5$

So Max binding stress $=7.1 \mathrm{~N} / \mathrm{mm}^{2} \times 5=\underline{\underline{35.5 \mathrm{~N} / \mathrm{mm}^{2}}}$

The material that can withstand this stress with low cost is aluminum

\subsubsection{Design of Frame}

The frame helps to carry modules and the module attached to the frame by freely movable pin. The force and stress analysis on frame are the same as the link (where the sheet metal welded) but here welding strength also considered. The frame made from four link or plate welded at the corner and the cross-section is hollow square with dimension of $40 \mathrm{~mm} \times 40 \mathrm{~mm}$. The frame is rectangular with the longest link length is $2.5 \mathrm{~m}$ and the smallest one is $2 \mathrm{~m}$ with the thickness of $2 \mathrm{~mm}$ so the design is based on the longest link.

\subsubsection{Force Analysis on the frame}

The wind force exerted on the link is

$$
\mathrm{F}=\mathrm{P} \times \mathrm{A}=135 \times(2.5 \times 0.04)
$$

where $\mathrm{A}=$ the perpendicular face of link to the wind

$$
\begin{aligned}
& \mathrm{F}=\underline{13.5 \mathrm{~N}} \\
& \mathrm{P}=\text { the wind pressure }
\end{aligned}
$$

\subsubsection{Stress Analysis on the frame}

The stress induced in the frame link is bending stress $\sigma_{\boldsymbol{b}}=\frac{\boldsymbol{M}_{\max }}{\boldsymbol{Z}}$ but the maximum allowable stress of the material of ordinary cast iron can be $\boldsymbol{\sigma}_{\text {allowable }}=56 \mathrm{MPa}$ [2]

The maximum bending moment $\left(\boldsymbol{M}_{\max }\right)=\frac{\boldsymbol{F} \times \boldsymbol{L}}{\mathbf{4}}=\frac{\mathbf{1 3 . 5 \times 2 5 0 0}}{\mathbf{4}}=\underline{\underline{8,437.5 \mathrm{Nmm}}}$

Thus, section modulus is, $\mathrm{Z}=\frac{\boldsymbol{b}^{\mathbf{4}}-\boldsymbol{h}^{\mathbf{4}}}{\mathbf{6 b}}=\frac{\mathbf{4 0}^{\mathbf{4}}-\mathbf{3 6 ^ { 4 }}}{\mathbf{4 0 \times 6}}=3668 \mathbf{m m}^{\mathbf{3}}$

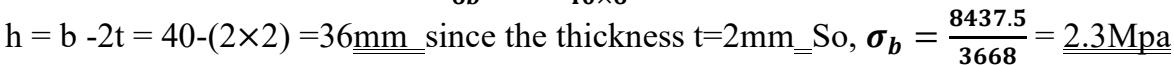

Thus, since, $\boldsymbol{\sigma}_{\text {allowable }}>\boldsymbol{\sigma}_{\boldsymbol{b}}$ the we say that our design is safe [2and3]

Based on the cost, availability and its ability to withstand the above stress cast iron is selected for our design purpose.

\subsubsection{Design of Follower and Cam}

A cam is a rotating machine element which gives reciprocating or oscillating motion to another element known as follower. The cam and the follower have a line contact and constitute a higher pair. The cams are usually rotated at uniform speed by a shaft, but the follower motion is predetermined and will be according to the shape of the cam. In this design the cam has reciprocating motion and the follower follow the profile. The cam and follower are one of the simplest as well as one of the most important mechanisms found in modern machinery today. The main purpose of the cam in this design is to control the opening and closing of the module which is found on the rectangular frame where the winds strike. 


\subsubsection{Design of Cylindrical Cam}

* The cam is hollow shaped and has roller in the interior part which travel through the profile on the follower.

* It has hole for rope to tight and connect with the base of reciprocating plate therefore the motion of plate directly transferred to up-down movement of cylindrical cam

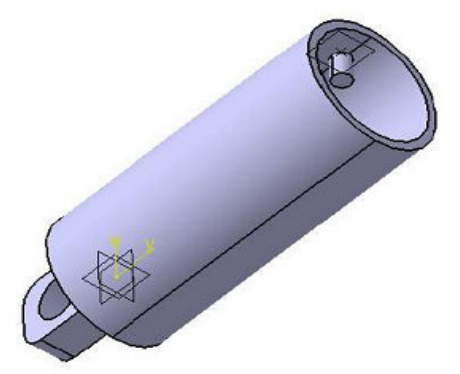

Outer diameter $(\mathrm{Do})=96 \mathrm{~mm} \quad$ Inner diameter $(\mathrm{Di})=92 \mathrm{~mm}$

Steel 40C8 is selected due to its good wearing resistance property which has the maximum allowable shear stress of $\tau_{\text {allowable }}=192 \mathrm{Mpa}$

\subsubsection{Stress Analysis on cylindrical cam}

The cylindrical cam has reciprocating motion due to the pulling rope and pushing spring. In this motion maximum stress induced in the roller (which is attached to the cylinder internally) because when it moves downward by pulling the rope through the profile it compresses the spring or resist the spring force. If the roller is unable to resist the stress, it is sheared off. The resistance offered by a roller to be sheared off is known as shearing resistance or shearing strength or shearing value of the roller. We know that shearing area or the area of the roller to be sheared off can be;

$\mathbf{A}_{\mathbf{s}}=\frac{\pi}{\mathbf{4}} \times \mathbf{d}^{2} \quad$ Where $\quad \mathrm{d}=$ diameter of roller inside the hole of the cam profile $=15 \mathrm{~mm}$

$\mathbf{A}_{\mathbf{s}}=\frac{\boldsymbol{\pi}}{\mathbf{4}} \times \mathbf{1 5}^{\mathbf{2}} \quad$ There fore $\mathbf{A}_{\mathbf{s}}=\underline{\underline{176.7 \mathrm{~mm}^{2}}}$

The shearing force that is exerted on the roller in cylindrical cam is equal to the maximum force exerted on rectangular plate by the wind.

$F_{\text {max }}=\frac{P_{\max }}{V_{\text {max }}}=\frac{10125 \mathrm{~J} / \mathrm{s}}{15^{\mathrm{m}} / \mathrm{s}}=\underline{\underline{675 \mathrm{~N}}}$

Thus, the shearing force $\left(\mathrm{F}_{\mathrm{s}}\right)$ or the maximum force required to shear of the pulling cam is equal to the maximum force exerted on the rectangular plate by the wind.

$\mathrm{F}_{\mathrm{s}}=\mathbf{A}_{\mathbf{s}} \times \boldsymbol{\tau} \Longrightarrow \boldsymbol{\tau}=\frac{\mathrm{Fs}}{\mathbf{A}_{\mathbf{s}}} \quad$ So, $\boldsymbol{\tau}=\frac{675 \mathrm{~N}}{176.7 \mathrm{~mm}^{2}}=\underline{\underline{3.28 \mathrm{Mpa}}}$

Therefore, since the shear stress induced in the roller by the effect of wind is smaller than the maximum allowable shear stress of the material of the roller then we say that our design is safe

$\left(\tau<\tau_{\text {allowable }} \Rightarrow 192\right.$ Mpa $>3.28$ Mpa) thus, the design is safe

\subsubsection{Design of Cylindrical Follower}

* This follower has profile to follow the predetermined motion and it has circular motion but it does not complete one revolution the maximum turning angle is 90 .

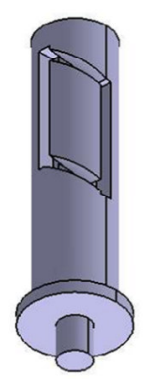

Figure 6: cylindrical follower drawn on Solid work Software

Diameter $(D)=80 \mathrm{~mm} \quad$ Diameter of spring seat $=92 \mathrm{~mm} \quad$ Material used $=$ cast iron

The vertical length of the profile is the difference between the free length and solid length of spring i.e

$$
\begin{aligned}
& \boldsymbol{L}_{\text {profile }}=\boldsymbol{L}_{\text {free length }}-\boldsymbol{L}_{\text {solid length }} \\
& \boldsymbol{L}_{\text {profile }}=450 \mathrm{~mm}-170 \mathrm{~mm} \quad \text { Thus, } \boldsymbol{L}_{\text {profile }}=\underline{\underline{280 \mathrm{~mm}}}
\end{aligned}
$$




\subsubsection{Design of the spring}

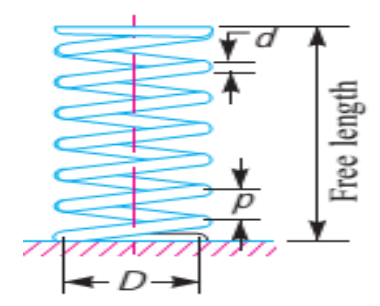

Figure 7: helical spring [2]

where, $\mathrm{D}=$ diameter of coil, $\mathrm{d}=$ diameter of wire and $\mathrm{P}=$ the pitch

\subsubsection{Force Analysis on The Spring}

The force exerted on spring by the cam profile due to the rope with reciprocating plate is

$$
\begin{aligned}
& \mathrm{F}=\frac{T}{r}=\frac{3375}{1.5}=\mathbf{2 2 5 0 N} \quad \text { where } \mathrm{T}=\text { The torque on rope } \\
& \mathrm{r}=\text { distance from center of rotation }
\end{aligned}
$$

Deflection of spring or the distance it compresses from its free length is $\boldsymbol{\delta}=\mathbf{2 8 0} \mathbf{m m}$

\subsubsection{Stress Analysis on Spring}

The stress induced on spring due to the axial force exerted by the rope are torsional shear stress direct shear stress, stress due to curvature of wire etc.

\subsubsection{Torsional Shear Stress}

The force tends to rotate the wire due to the twisting moment set up in the wire. Thus, torsional shear stress is induced in the wire.

$\tau_{1}=\frac{8 F D}{\pi d^{3}}=\frac{8 \times \mathbf{2 2 5 0} \times \mathbf{9 2}}{\pi \times 10^{3}}=\underline{\underline{527 \mathrm{~N} / \mathbf{m m}^{2}}}$ where, $\mathrm{F}=$ the force on spring

\subsubsection{Direct Shear Stress}

$\mathrm{D}=$ diameter of coil and $\mathrm{d}=$ diameter of wire $=10 \mathrm{~mm}$

We know that direct shear stress $\left(\tau_{2}\right)$ due to the force $(F)$ is $\tau_{2}=\frac{F}{A}=\frac{2250}{\frac{\pi}{4} \times \mathrm{d}^{2}}=\frac{4 \times 2250}{\pi \times 10^{2}}=\frac{28.7 \mathrm{~N}}{\mathrm{~mm}^{2}}$

Therefore, maximum shear stress induced in the wire can be calculated and is equal to $\tau_{\text {max }}=$ Torsional shear stress + Direct shear stress $=527+28.7=555.7 \mathrm{~N} / \mathbf{m m}^{2}$

\subsubsection{Terms Used In Compression Springs}

A. No of Active Term: We know that the stiffness of the spring or spring rate

$$
\mathrm{K}=\frac{\mathrm{F}}{\delta}=\frac{\mathbf{G} \times \mathbf{d}^{4}}{8 \times \mathbf{D}^{3} \times \mathbf{N}}
$$

$8=\frac{84 \times 10^{3} \times 10^{4}}{8 \times 92^{3} \times N}$

where, $\mathrm{G}=$ Modulus of rigidity for the spring material,

B. Solid Length When the compression spring is compressed until the coils come in contact with each other, then the spring is said to be solid.

Solid length of the spring $\left(\boldsymbol{L}_{\boldsymbol{s}}\right)=\mathrm{N} \times \mathrm{d}=17 \times 10=\underline{\underline{170 \mathrm{~mm}}}$

C. Free Length: The free length of a compression spring is the length of the spring in the free or unloaded condition[2,3]. $\mathbf{L}_{\mathbf{f}}=\mathbf{N} \times \mathbf{d}+\boldsymbol{\delta}=\mathbf{1 7 0}+\mathbf{2 8 0}=\mathbf{4 5 0 m m}$

D. Spring Index: The spring index is defined as the ratio of the mean diameter of the coil to the diameter of the wire. $\mathrm{C}=\frac{\mathrm{D}}{\mathrm{d}}=\frac{\mathbf{9 2}}{\mathbf{1 0}}=\mathbf{9 . 2}$

E. Pitch: The pitch of the coil is defined as the axial distance between adjacent coils in uncompressed state. $\mathrm{P}=\frac{L_{f}}{N}=\frac{450}{17}=26 \mathrm{~mm}$

\subsubsection{Buckling Of Compression Springs}

It has been found experimentally that when the free length of the spring (LF) is more than four times the mean or pitch diameter (D), then the spring behaves like a column and may fail by buckling at a comparatively low load.

Free length $>4 \times \mathrm{D}=4 \times 92=\underline{\underline{368 \mathrm{~mm}}}$ Thus, $\Rightarrow 450 \mathrm{~mm}>368 \mathrm{~mm}$

It orders to avoid the buckling of spring; it is either mounted on a central rod or located on a tube. In this design the spring is located in the cylindrical cam so the buckling problem cannot be created.

3.1.6 Selection of Steel Wire Rope for Cam Mechanism

Known values in the steel wire rope are: Breaking tensile stress $\left(\boldsymbol{\sigma}_{\mathrm{br}}\right)$ of steel wire $=160 \mathrm{kgf} / \mathbf{m m}^{2}$, tension in the $\operatorname{rope}(\mathrm{s})=2250 \mathrm{~N}=225 \mathrm{kgf}$,number of bend $(\mathrm{n})=1$,

Take number of wire $(\mathrm{i})=222$ standard And safety factor for medium duty power operated mechanism $(\mathrm{k})=6$

$\mathbf{A}_{\mathbf{2 2 2}}=\frac{\mathrm{s}}{\frac{\sigma_{\mathbf{b r}}}{\mathbf{k}} \times-\frac{\mathbf{d}}{\mathbf{D}_{\min }} \times \mathbf{3 6 0 0 0}}=\underline{\underline{54 \mathbf{m m}^{2}}}$. Then by taking the nearest cross-section from standard i.e. $62.8 \mathbf{m m}^{2}$ we can get all the dimensions of the wire rope are as follow . 
Rope diameter $=13 \mathrm{~mm}$, Wire diameter $=0.60 \mathrm{~mm}$, Weight $=0.59 \mathrm{kgf} / \mathrm{m}$ and Strength of the steel wire rope $=10050 \mathrm{~kg}$ 3.1.7 Design of Rod.

The Force acting on the rod can be calculated as;

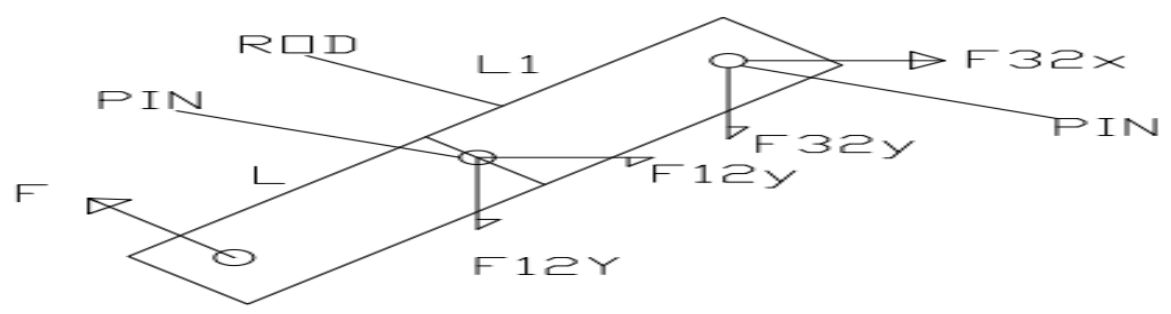

Figure 8: Force analysis on rod

From dimensional analysis the force acting on the fulcrum point $\mathrm{F}$ and point $\mathrm{B}$ is known

$\mathrm{F} 32 \mathrm{x}=-1688 \mathrm{~N} \quad \mathrm{~F} 12 \mathrm{x}=1688 \mathrm{~N}$

$\mathrm{F} 32 \mathrm{y}=1940 \mathrm{~N} \quad \mathrm{~F} 12 \mathrm{y}=1940 \mathrm{~N}$

The resultant force at point $\mathrm{F}$ and $\mathrm{B}$ is equal to

$\mathrm{R}=\sqrt{F X^{2}+F Y^{2}}=\sqrt{1,940^{2}+1, \mathbf{6 8 8}^{2}}=\sqrt{\mathbf{6 , 6 1 2 , 9 4}} 4=2,571.56 \mathrm{~N}$

To determine the force acting on the point $\mathrm{A}(\mathrm{P})$

Taking moment about at fulcrum point $\mathrm{F}$

$\mathrm{P} \times \mathrm{L}=\mathrm{R} \times \mathrm{L} 1=\mathrm{P} \times 3 \mathrm{~m}=2571.56 \mathrm{~N} \times 1.5 \mathrm{~m}$ then solving $\quad \mathrm{P}=\frac{2517.56 \mathrm{~N} \times 1.5 \mathrm{~m}}{3 \mathrm{~m}}=\underline{\underline{1258.78 \mathrm{~N}}}$

The material selected for pin and rod was Steel- 37

3.1.8 Design of Connecting Rod

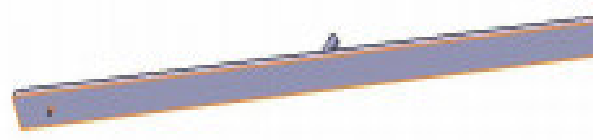

Figure 9: connecting rod drawn on Solid work

The material selected for connected load was mild steel.

\subsubsection{Force Analysis of Connecting Rod}

Due to the torque the links may buckle in the vertical plane. To prevent buckling in the vertical plane (i.e. in the plane of the link) the links are may be considered as hinged at both ends. Wealready know that the resultant forces on this link $\mathrm{F}=5142$.Assume factor of safety $(\mathrm{Fos})=3$ the links must be designed for a buckling load $(\mathrm{Wcr})=5142 \times 3=15426 \mathrm{~N} / \mathrm{mm}$.

Assuming that the width of the link is three times the thickness of the link, i.e. $b=3$ therefore cross-sectional area of the link,

$\mathrm{A}=\mathrm{t} \times 3 \mathrm{t}=3 \mathrm{t}^{2}$ and moment of inertia (I) of the cross-section of the link,

$\mathrm{I}=\frac{\mathbf{1}}{\mathbf{1 2}} \times \mathrm{t} \times \mathrm{b}^{3}=\frac{\mathbf{1}}{\mathbf{1 2}} \times \mathrm{t} \times 3 \mathrm{t}^{3}=2.25 \mathrm{t}^{4}$ we know that radius of gyration

$\mathrm{K}=\sqrt{\frac{I}{A}}=\sqrt{\frac{2.25 \times t^{4}}{3 \times t^{2}}}=0.866 \mathrm{t}$

Since for buckling of the link in the vertical plane, the ends are considered as hinged, therefore equivalent length of the link $(\mathrm{L})=2.294 \mathrm{~m}$ and Rankin constant $\mathrm{a}=\frac{\mathbf{1}}{\mathbf{7 5 0 0}}$

According to Rankin's formula, buckling load (Wcr) from sub title 3.1.8.1

$15426=\frac{\sigma \mathrm{c} \times \mathrm{A}}{1+a\left(\frac{L}{K}\right) 2}=\frac{320 \times 3 \times t^{2}}{1+\left(\frac{1}{7500}\right) \times\left(\frac{2294}{0.866 t}\right) 2}=\frac{960 \times t^{2}}{1+\frac{938}{t 2}} \Rightarrow \frac{15426}{936}=\frac{t 4}{t^{2}+936}$

$\mathrm{t}^{4}-16 \mathrm{t}^{2}-16 \times 936=0$

$\mathrm{t}^{2}=16+\frac{\sqrt{16^{2}+4 \times 16 \times 936}}{2}=\frac{16+242}{2}=258 / 2$ solving for $\mathrm{t}=\sqrt{\mathbf{1 2 9}}=11.35 \mathrm{~mm}$

So the width will be, $b=3 \mathrm{t}=3 \times 11.35=34 \mathrm{~mm}$

3.1.8.2 Stress Analysis of Connecting Rod

Let us calculate mass of the material first

$\mathrm{m}=$ Volume $\times$ density $=$ Area $\times$ length $\times$ density $=A \times L \times \rho=3 t^{2} \times 1 \times 7800$

$\mathbf{m}=23400 \times(0.011)^{2} \times 2.294 \Rightarrow \mathrm{m}=\underline{\underline{6.5 \mathrm{~kg}}}$

$\therefore \quad$ Maximum bending moment $\left(\mathrm{M}_{\max }\right)=\mathrm{m} \omega^{2} \times \mathrm{r} \times \frac{\mathbf{1}}{\mathbf{9 \sqrt { 3 }}} \Rightarrow \mathrm{M}_{\max }=6.5 \times 36 \times 0.434 \times \frac{\mathbf{5 . 2 6}}{\mathbf{9} \sqrt{3}}=\underline{\underline{34.28 \mathrm{Nm}}}$ and Section $\operatorname{modulus}(\mathrm{Z})=\frac{\mathrm{I}}{\mathrm{y}}=\frac{\mathbf{1}}{\mathbf{6}} \times t \times \mathrm{b}^{2}=\frac{\mathbf{1}}{\mathbf{6}} \times \mathrm{t} \times(3 \mathrm{t})^{2}=\frac{\mathbf{9} \mathbf{t}^{3}}{\mathbf{6}}=1.5 \times(0.01142)^{3}=1.5 \times 1.4 \times 10^{-6}$ 


$$
\mathrm{z}=\underline{\underline{2.23 \times 10^{-6} \mathrm{~mm}^{3}}}
$$

Maximum bending or whipping stress due to inertia bending forces $\left(\sigma_{b(\max )}\right)$

$\left.\sigma_{b(\max )}\right)=34.28 \mathrm{Nm} 2.23 * 10-6=15.34 \mathrm{MPa}$

$\sigma_{b(\max )}=\frac{34.28 \mathrm{Nm}}{2.23 * 10^{-6}}=15.34 \mathrm{Mp}$

$\sigma_{b(\max )}=\frac{M_{\max }}{Z_{x x}} \quad \sigma_{b(\max )}=15.34 \mathrm{MPa}$ which is less than $320 \mathrm{Mpa}$ and thus the design is safe.

The maximum compressive stress $\left(\sigma_{c} \max \right)$ in the connecting rod will be,

$\sigma_{c}(\max )=$ Direct compressive stress + Maximum bending stress

$\sigma_{c}(\max )=\frac{F}{A}+\frac{M}{Z}=\frac{15426}{\left(3.86 \times 10^{-4}\right)}+15.34 \mathrm{Mp}=\underline{\underline{399}, 169.2 \mathrm{Mpa}}$ which is maximum compressive stress being less than allowable stress of the material therefore the design is safe.

\subsubsection{Design of Flywheel}

\subsubsection{Force Analysis of Flywheel}

A flywheel used in machines serves as a reservoir which stores energy during the period when the supply of energy is more than the requirement and releases it during the period when the requirement of energy is more than supply. A little consideration will show that when the flywheel absorbs energy, its speed increases and when it releases, the speed decreases. Hence in this design the flywheel does not maintain a constant speed, it simply returns the plate to its original position or to create backward motion. Being the wind strikes the plate then the plate moves in the direction of wind i.e. it create forward motion and some of energy of wind stored in the flywheel which is used to return the plate i.e. it creates backward motion.

The average wind power (pav )absorbed by the plate is

$$
\mathrm{P}_{\mathrm{av}}=\frac{1}{2} \times \rho \times \mathrm{A}^{\circ} \mathrm{v}^{3}=0.5 \times 1.2 \times 5 \times 5^{3}=\underline{\underline{2,187 \mathrm{watt}}}
$$

The force exerted by wind on the plate $\left(\mathrm{F}_{\mathrm{av}}\right)=\frac{\mathrm{p}_{\mathrm{av}}}{\mathrm{v}_{\mathrm{av}}}=\frac{2187}{9}=243 \mathrm{~N}$

The average torque $\left(\mathrm{T}_{\mathrm{av}}\right)$ created on plate due to wind, $\mathrm{T}_{\mathrm{av}}=\mathrm{F}_{\mathrm{av}} \times \mathrm{r}=243 \times 5=1215 \mathrm{Nm}$

The angular velocity $\left(\omega_{\mathrm{av}}\right)$ of the plate is $\omega_{\mathrm{av}}=\frac{\mathrm{p}_{\mathrm{av}}}{\mathrm{T}}=\frac{2,187}{1,215}=1.8 \frac{\mathrm{rad}}{\mathrm{se}}$

\subsubsection{Stresses in A Flywheel Rim}

A flywheel, as shown in Figure 10 consists of a rim at which the major portion of the mass or weight of flywheel is concentrated, a boss or hub for fixing the flywheel on to the shaft and a number of arms for supporting the rim on the hub. So, stresses such as tensile stress due to centrifugal force, tensile bending stress caused by the restraint of the arms, and shrinkage stresses due to unequal rate of cooling of casting are induced in the rim of a flywheel. These stresses may be very high but there is no easy method of determining. This stress is taken care of by a factor of safety.

3.1.9.2.1 Tensile stress due to the centrifugal force: The tensile stress in the rim due to the centrifugal force, assuming that the rim is unstrained by the arms, is determined in a similar way as a thin cylinder subjected to internal pressure. Let $b=$ Width of rim, $t=$ Thickness of rim, $A=$ cross-sectional area of rim, $D=$ =mean diameter of fly wheel, $\mathrm{R}=$ mean radius of flywheel,

$\rho=$ density of flywheel, $\omega=$ anguler velocity of flywheel, $\mathrm{V}=$ linear velocity of flywheel and $\sigma_{t}=$ tensile or hoop sterss
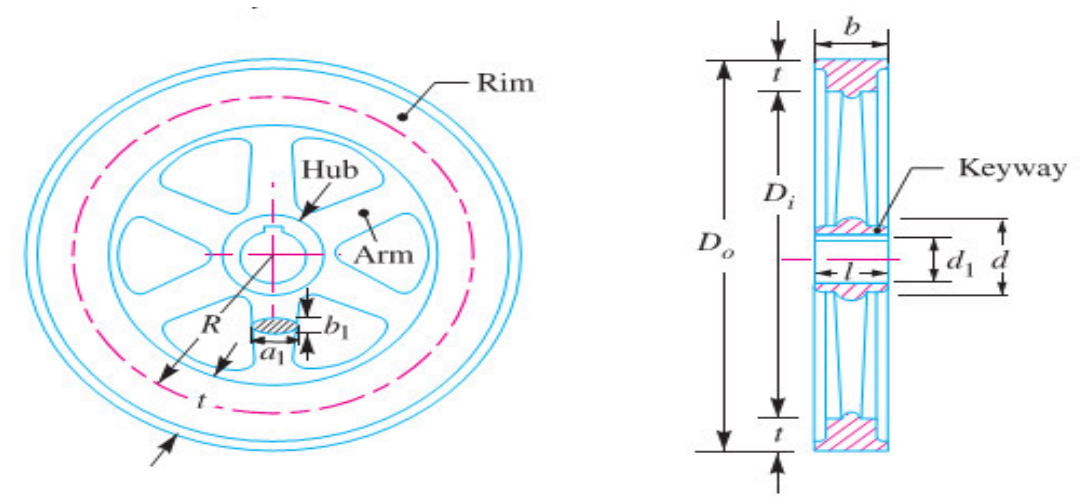

Figure 10: flywheel [2]

Tensile or hoop stress can be calculated as follows: $\boldsymbol{\sigma}_{\boldsymbol{t}}=\boldsymbol{\rho} \times \boldsymbol{R}^{\mathbf{2} \times} \boldsymbol{\omega}^{\mathbf{2}}=6800 \times \mathbf{0 . 4 3 4 ^ { 2 }} \times \mathbf{9}^{\mathbf{2}}=103,746.5 \mathrm{~N} / \boldsymbol{m}^{\mathbf{2}}$

\subsection{Tensile bending stress caused by restraint of the arms}

The tensile bending stress in the rim due to the restraint of the arms assumes that each portion of the rim between a pair of arms behaves like a beam fixed at both ends and uniformly loaded such that length between fixed ends: $\mathrm{L}=\frac{\pi \times \mathbf{D}}{\mathrm{n}}=\frac{\pi \times 434 \times 2}{6}=\underline{\underline{45 \mathrm{~mm}}}$ 
where, $\mathrm{L}=$ number of arms .

The uniformly distributed load $(\mathrm{w})$ per meter length will be equal to the centrifugal force between a pair of arms. This distributed load induces bending stress and this bending stress is calculated by

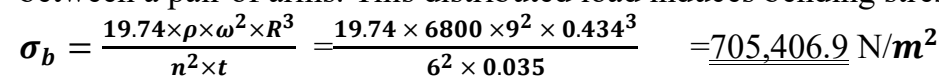
Now total stress in the rim can be calculated as follows; $\boldsymbol{\sigma}=\boldsymbol{\sigma}_{\boldsymbol{t}}+\boldsymbol{\sigma}_{\boldsymbol{b}}=103,746.5 \mathrm{~N} / \boldsymbol{m}^{2}+705,406.9 \mathrm{~N} / \boldsymbol{m}^{2}=809,153.4 \mathrm{~N} / \boldsymbol{m}^{2}$

Due to the centrifugal force acting on the rim, the arms will be subjected to direct tensile stress whose magnitude is same as discussed in the previous article.

Therefore, Tensile stress in the arms, $\sigma_{\mathrm{tl}}=\frac{3}{4} \times \boldsymbol{\sigma}_{\mathrm{t}}=\frac{3}{4} \times 103,746.5 \mathrm{~N} / \mathbf{m}^{2}=77,809.9 \mathrm{~N} / \mathbf{m}^{2}$

\subsection{Bending stress due to the torque transmitted}

Due to the torque transmitted from the rim to the shaft or from the shaft to the rim, the arms will be subjected to bending, because they are required to carry the full torque load. In order to find out the maximum bending moment on the arms, it may be assumed as a cantilever beam fixed at the hub and carrying a concentrated load at the free end of the rim as shown in

Let $\mathrm{T}=$ Maximum torque transmitted by the shaft $=$ Mean radius of the rim $r=$ Radius of the hub, $\mathrm{n}=$ Number of arms, and $Z=$ Section modulus for the cross-section of arms

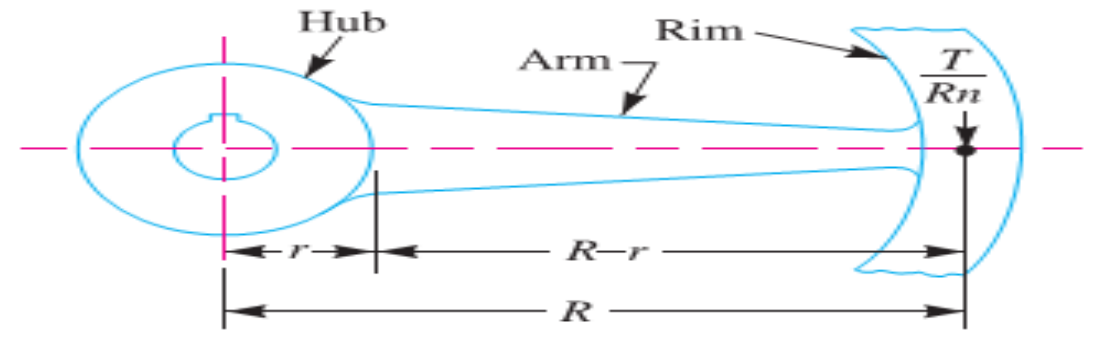

Figure 11: Arm [2]

Bending stress in arms, $\boldsymbol{\sigma}_{\boldsymbol{t} \boldsymbol{l}}=\frac{\boldsymbol{M}}{\boldsymbol{Z}}=\frac{\boldsymbol{T}(\boldsymbol{R}-\boldsymbol{r})}{\boldsymbol{R} \boldsymbol{Z} \boldsymbol{}}=\frac{\mathbf{1 1 1 6}(\mathbf{0 . 4 3 4 - \mathbf { 0 . 0 4 } )}}{\mathbf{0 . 4 3 4} \times \mathbf{6} \times \mathbf{3 0 3 8 2}}=5,557,752.4 \mathrm{~N} / \mathrm{m} 2$

Total tensile stress in the arms of the hub end $: \sigma=\sigma_{t l}+\sigma_{b l}$

$\boldsymbol{\sigma}=5,557,752.4 \mathrm{~N} / \mathrm{m} 2+77,809.9 \mathrm{~N} / \boldsymbol{m}^{2}=5,635,562.4 \mathrm{~N} / \mathrm{m} 2=5.6 \mathrm{~N} / \mathrm{mm} 23.2 .16$ Design of 3.1.9.3 Flywheel Arms The cross-section of the arms is usually elliptical with major axis as twice the minor axis, as shown in Fig and it is designed for the maximum bending stress.

Let $\mathrm{a}=$ Major axis, and $\mathrm{b}=$ Minor axis.

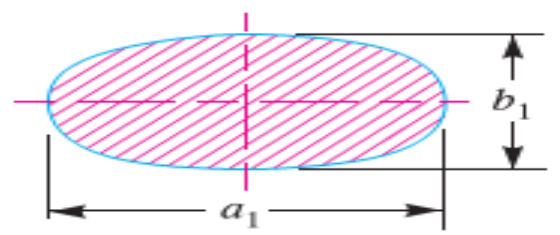

Figure 12: flywheel arm cross section[2]

Section modulus $(\mathrm{Z})=\frac{\pi}{32} \times b_{1} \times\left(b_{1}\right)^{2}$

$\mathrm{Z}=\frac{\pi}{32} \times 0.5 \times \mathrm{a}_{1}\left(\mathrm{a}_{1}{ }^{2}\right)=0.05 \mathrm{a}_{1}{ }^{3}$

We know that maximum bending moment $\left(\mathrm{M}_{\mathrm{b}}\right)$ can be calculated as, $\mathrm{M}_{\mathrm{b}}=\frac{\mathbf{T}}{\mathbf{R} \times \mathbf{n}}(\mathbf{R}-\mathbf{r})$

$\mathrm{M}_{\mathrm{b}}=\frac{\mathbf{1 1 1 6}}{\mathbf{0 . 4 3 4 \times 6}} \times(\mathbf{0 . 4 3 4}-\mathbf{0 . 0 8})=151.7 \mathrm{Nm}$

Maximum bending stress can be found, $\boldsymbol{\sigma}_{\mathbf{b}}=\frac{\mathbf{M}}{\mathbf{Z}}=\frac{\mathbf{T}}{\mathbf{R} \times \mathbf{n} \times \mathbf{Z}}(\mathbf{R}-\mathbf{n})$.

$\sigma_{\mathrm{b}}=\frac{151,717.3}{0.05 \times \mathrm{a}_{1}{ }^{3}}=5.93 \mathrm{Mpa}$

For $\mathbf{a}_{\mathbf{1}}=\mathbf{8 0} \mathrm{mm}$, assuming, $\mathbf{b}_{\mathbf{1}}=\mathbf{0 . 5} \mathbf{a}_{\mathbf{1}}$ the dimensions of the arms may be obtained from eq (1) and eq (2) and bending stress of material is $5 \mathrm{Mpa}$.Therefore, $\mathbf{b}_{\mathbf{1}}=\mathbf{4 0} \mathbf{~ m m}$

\subsubsection{Design of Shaft and Hub of Flywheel}

The diameter of shaft for flywheel is obtained from Maximum shear stress theory or Guest's theory. It is used for ductile materials such as mild steel. We know that the maximum torque transmitted by shaft is $\mathbf{T}_{\max }=\mathbf{1 1 1 6} \mathbf{N m}$ $=1,116,000 \mathrm{Nmm}$

The binding moment on cantilever shaft at the end due to the mass of flywheel is

$\mathbf{M}_{\max }=\mathbf{W} \times \mathbf{L}=\mathbf{3 0 0} \mathbf{N} \times \mathbf{3 0 0} \mathbf{m m}=90,000 \mathrm{Nmm}$ 
The equivalent twisting moment, $\mathbf{T}_{\mathrm{e}}=\sqrt{\mathbf{T}_{\max }{ }^{2}+\mathbf{M}_{\max }{ }^{2}}=\sqrt{\mathbf{1 1 1 6 0 0 0}^{2}+\mathbf{9 0 0 0 0}^{2}}$

$\mathrm{Te}=\underline{1,119,623.1 \mathrm{Nmm}}$

Take material of carbon steel of grade $40 \mathrm{C}$ and its allowable shear stress $(\boldsymbol{\tau})$ is $192 \mathrm{Mpa}$

The equivalent twisting moment (Te) can also given by $\mathbf{T}_{\mathbf{e}}=\frac{\mathbf{\pi}}{\mathbf{1 6}} \times \mathbf{\tau} \times \mathbf{d}^{\mathbf{3}}$. So solving for diameter of hub $\mathrm{d}=$ $\sqrt[3]{\frac{16 \times T_{\mathbf{e}}}{\pi \times \tau}}=30 \mathrm{~mm}$

The diameter of hub is usually taken as twice the diameter of shaft and length from 2 to 2.5 times the shaft diameter. It is generally taken equal to width of the rim.

$$
\mathbf{d}=\mathbf{2} \times \mathbf{d}_{\mathbf{1}} \quad \mathrm{L}=\mathrm{b}=70 \mathrm{~mm} \quad \mathbf{d}=\mathbf{2} \times \mathbf{4 0}=80 \mathrm{~mm}
$$

Where $\mathbf{d}_{\mathbf{1}}=$ diameter of shaft, $\mathrm{L}=$ length of hub

\subsubsection{Design and Selection of belts, gears and bearing}

Flat belt: The flat belt select because mostly used in the factories and workshops, where a moderate amount of power is to be transmitted, from one pulley to another when the two pulleys are not more than 8 meters apart. The standard flat belt thicknesses are 5, 6.5, 8, 10 and $12 \mathrm{~mm}$. Therefore, we selected from the standards having thicknesses of $5 \mathrm{~mm}$ for nominal belt widths of 35 to $63 \mathrm{~mm}$ because of our power to be transmitted is low.

Super gear and ball bearing were selected

\subsubsection{Design of Tower}

As shown in the Figure13 the basement (tower) carries each component of wind power harvest. The horizontal (the top) one carries two components thus are flywheel in one side and the blade on another with connecting rode. There is also a plate attached to the bottom of the vertical one which carries pulley, gear and generator. Therefore, it has to be strong and design at high factor of safety.

Figure 12: Tower drawn on Solid work Software

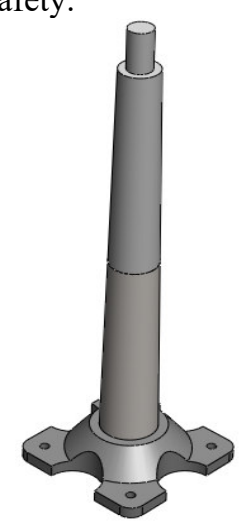

\subsubsection{Force Analysis on The Tower}

All force that act on the tower are:

* The wind force $F_{w}=675 \mathrm{~N}$ and Mass of plate $m_{p}=15 \mathrm{~kg}$

* Mass of rod $m_{r}=47 \mathrm{~kg}$ and Mass of connecting rod $m_{c r}=6.5 \mathrm{~kg}$

* Mass of flywheel $m_{f}=30 \mathrm{~kg}$ and Mass of gear, pulley and generator $\cong 100 \mathrm{~kg}$

\subsubsection{Stress Analysis for The Tower}

There are two common type of stress induce in the tower the first one is bending stress and the other one is compressive stress. As explained above the tower has two components vertical and horizontal rod. The horizontal rod experience bending stress but the vertical rod experience both bending and compressive stress. Thus, stress induces due to the wind force and the mass of each component flywheel, blade, generator and etc. The design is based on the maximum stress induce in the component.

\subsubsection{Stress in The Vertical Component of Tower}

Compressive stress is the stress induces in the vertical component of the tower due to the mass it carries and the cross section of the tower is circular but it is hollow. We select a material of 40c8 steel for the tower that has the ultimate tensile or compressive strength of $560-670 \mathrm{Mpa}$ the material (i.e. $\sigma_{u l t}=560 \mathrm{Mpa}$ ). The total load applied to the tower can be the sum of mass of pulley, connecting rod fly wheel, generator and mass of plate which is equals to $200 \mathrm{Kg}$

Thus, $\mathrm{F}=\mathrm{m} * \mathrm{~g}=10 * 200=2000 \mathrm{~N}$

Take factor of safety (fs) $=3$ and Therefore, the force(F) will be $6000 \mathrm{~N}$

The cross section of the tower is circular hollow with $50 \mathrm{~mm}$ outer diameter and $2 \mathrm{~mm}$ thickness.

$$
\mathrm{A}=\frac{\pi}{4} \times\left(D o^{2}-D i^{2}\right)=\frac{\pi}{4} \times\left(50^{2}-46^{2}\right)=384 \mathrm{~mm}^{2}
$$


So, the compressive stress will be $\sigma_{c}=\frac{F}{A}=\frac{6000 \mathrm{~N}}{384 \mathrm{~mm}^{2}}=16 \mathrm{MPa}$

The vertical component not only experience compressive stress but also bending stress due to the wind force. $\sigma_{b}=$ $\frac{M}{Z} \quad$ Where, $\mathrm{M}=$ maximum bending moment, $\mathrm{Z}=$ section modulus

$$
\mathrm{L}=\text { height of tower }
$$

The maximum bending moment $(\mathrm{M})=\mathrm{F} \times \mathrm{L}=2000 \times 25 \mathrm{~mm}=50000 \mathrm{Nmm}$

Section modulus $(\mathrm{Z})=\frac{\pi}{32} \times \frac{\left(D o^{4}-D i^{4}\right)}{D o}=\frac{\pi}{32} \times \frac{\left(50^{4}-46^{4}\right)}{50}=3478 \mathrm{~mm}^{3}$

Therefore, the induced bending stress is, $\sigma_{b}=\frac{M}{Z}=\frac{50000}{3478}=15 \mathrm{MPa}$

The total stress induced in the tower is, $\sigma_{T}=\sigma_{c}+\sigma_{b}=15 \mathrm{MPa}+15 \mathrm{MPa}=30 \mathrm{MPa}$

Thus, since the total stress induced in the tower is less than the ultimate strength of the material the design is safe.

\subsection{Part and Assembly Drawing of Our Project}

\subsubsection{Part Drawing of the Main Component of Harvester}

$3 \mathrm{D}$ of the main components of the wind harvester (turbine)was drawn on solid work. Some drawing of the main parts is shown in figures (Figure 13 up to Figure 19) below

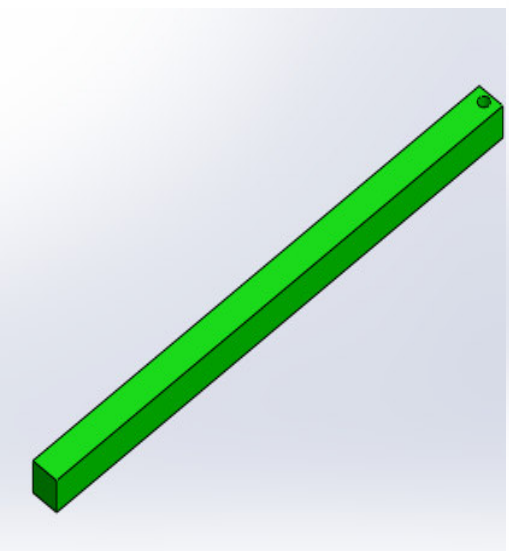

Figure 13: connecting rod

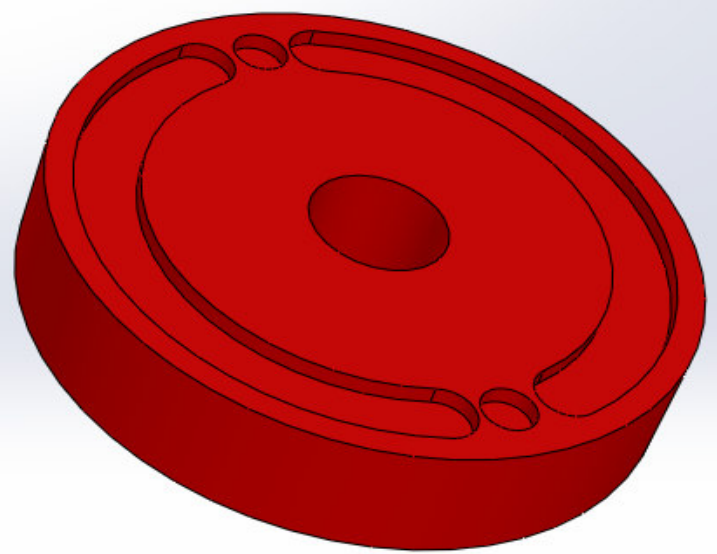

Figure 14: pulley

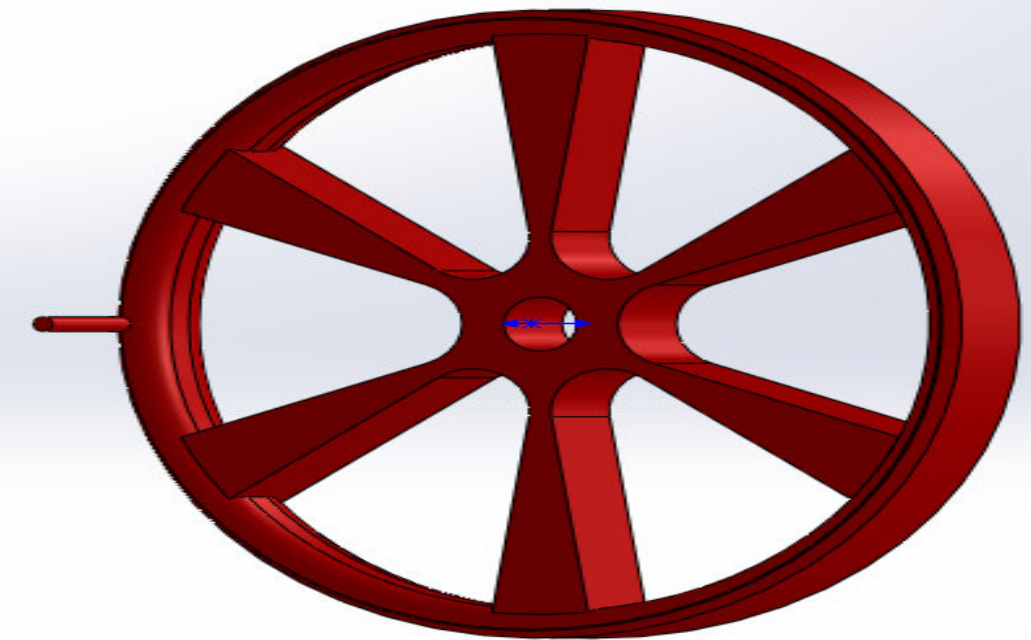

Figure 15: Flywheel 


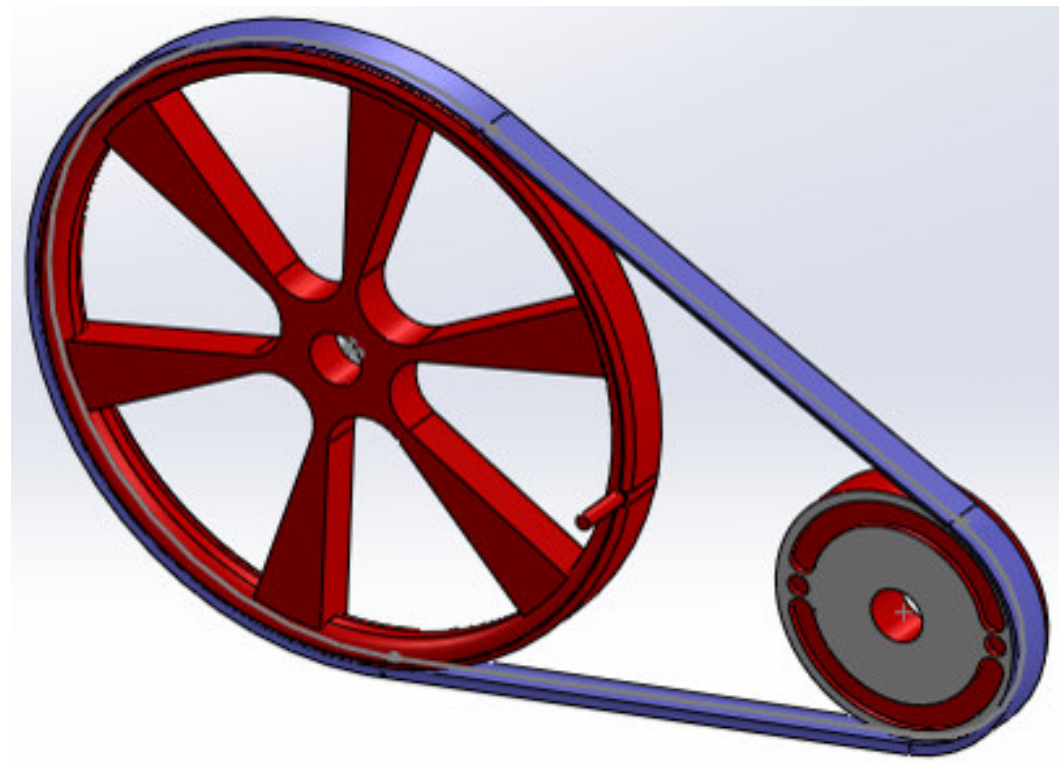

Figure 16: pulley belt arrangement

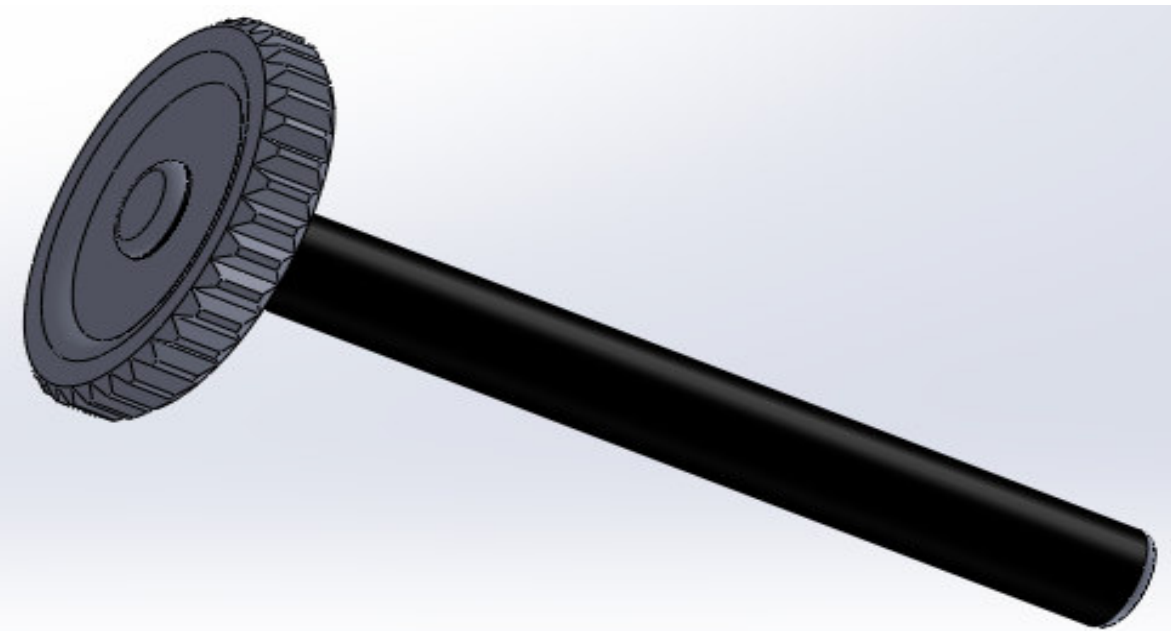

Figure 17: Gear Shaft Arrangement
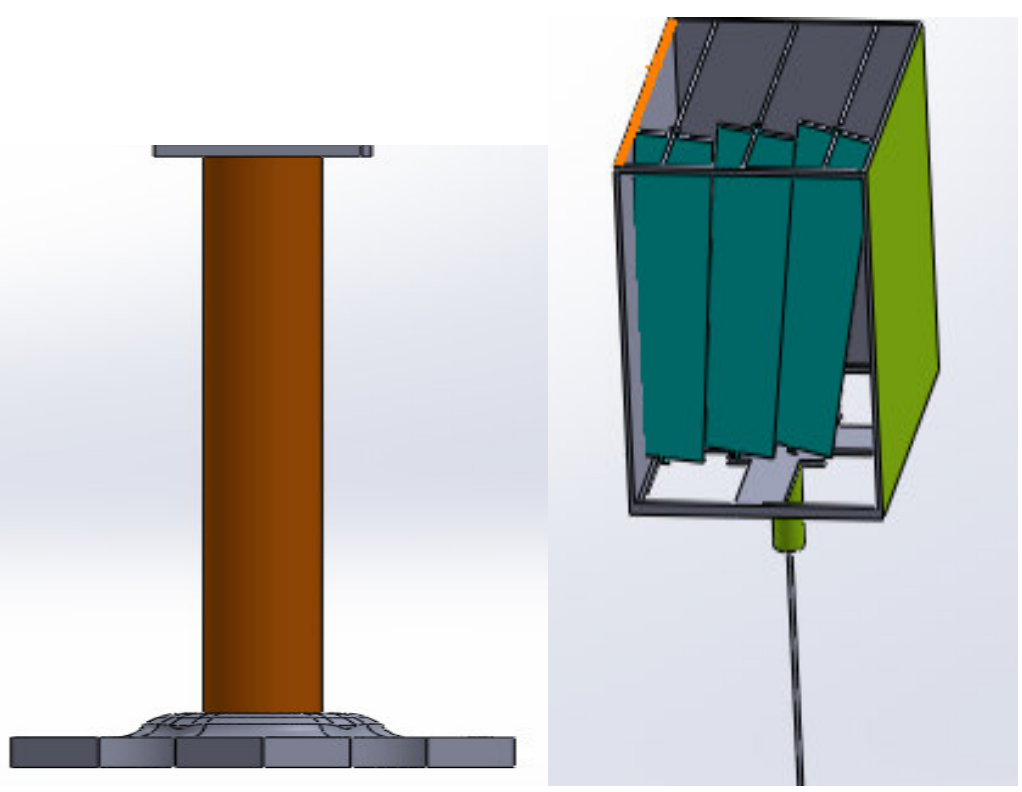

Figure 18: Tower and Rectangular Plate Housing 


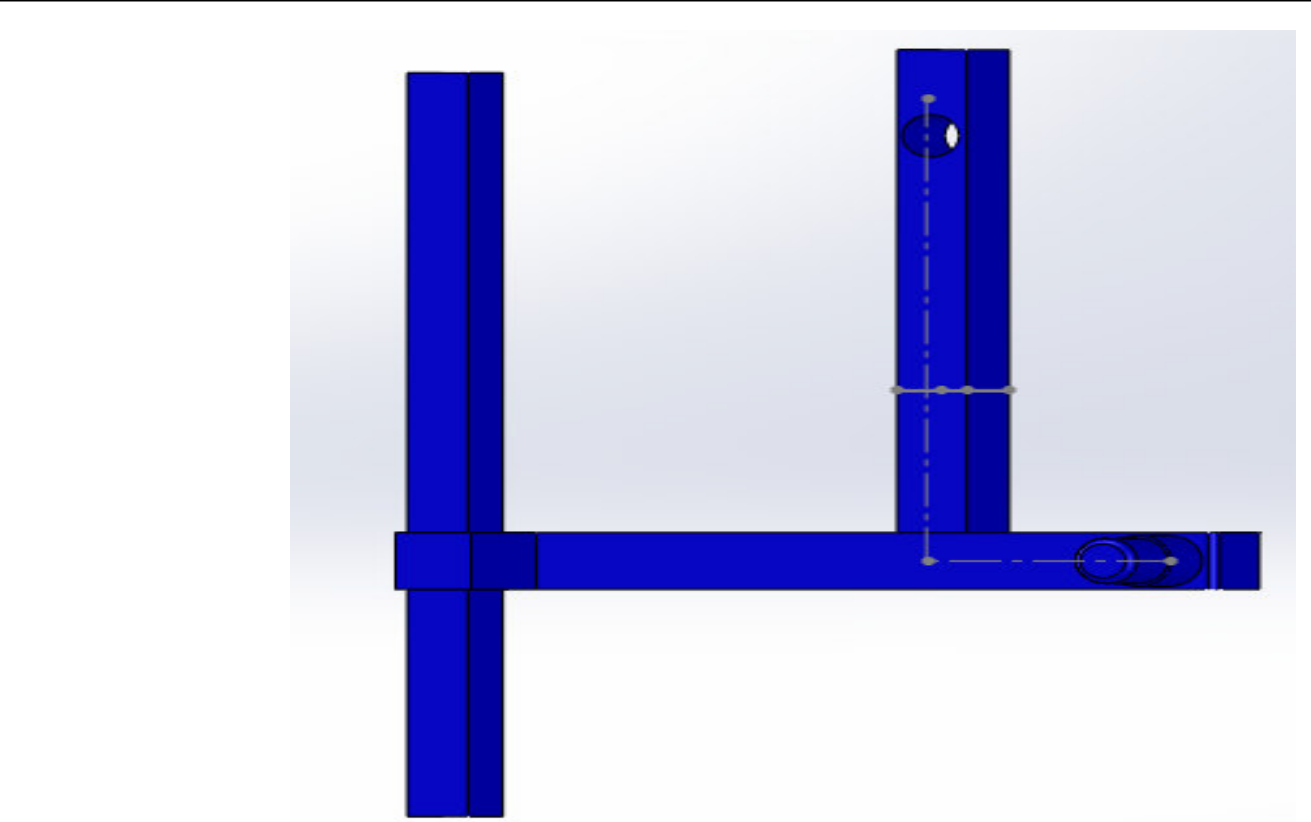

Figure 19: Module (Plate)

\subsubsection{Assembly Drawing of Our Project}

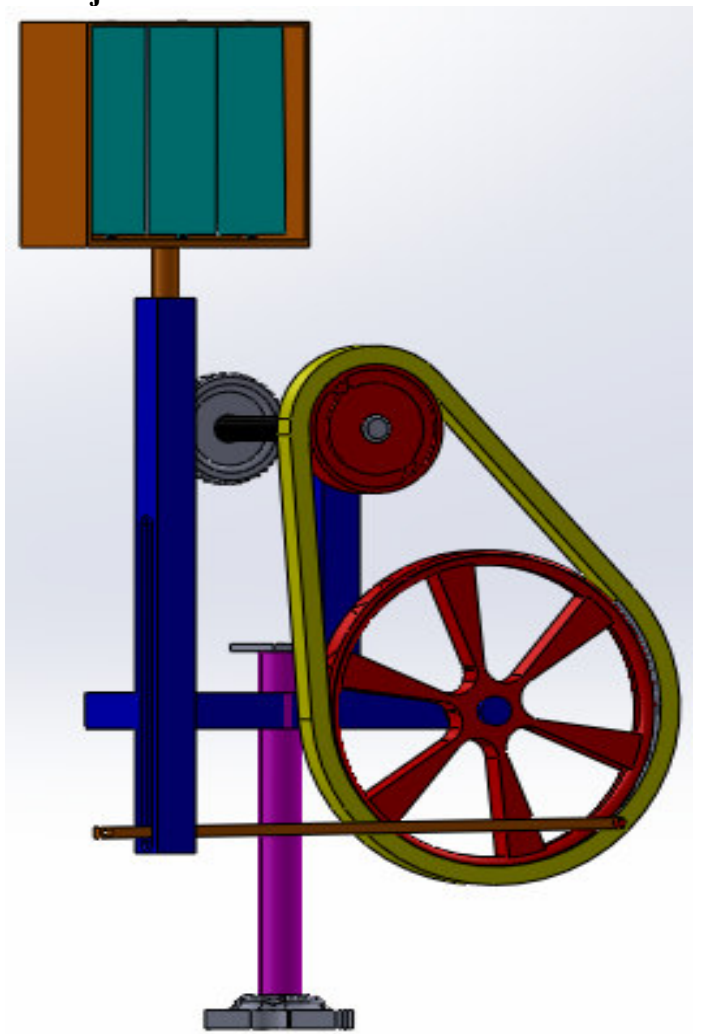

Figure 20: Assembly Drawing of Reciprocating Type Wind Power Harvester

\subsection{Working Principle of the Wind Harvester (turbine)}

When the vertically lifting rectangular plate opposing the direction of wind then the wind exerts some amount of force and push the plate forward to some distance. This rectangular plate is the combination of three small rectangular plates (modules). these plates move forward together and they never allow the wind pass $\mathrm{b} / \mathrm{n}$ them until the cam mechanism start to separate them. When the rectangular plate reaches at required position then the cam starts to operate. three plates separate each other and the wind pass $\mathrm{b} / \mathrm{n}$ them. So, the rectangular plates return back to its original position by the energy stored in the flywheel. The closing and separating condition of the rectangular plates (Modules) are controlled by the cam mechanism. always on the return condition modules are moving backward separately to decrease the force exerted on the surface of plates by allowing the wind pass $b / n$ 
them by turning the open surface to 90 degrees from its original position. Then this gained wind power transfer into the flywheel and converting the reciprocating motion into rotational motion by four bar linkage mechanism depends on grashofs principle. After converting the reciprocating motion into rotational motion, the rotating crank angular speed is multiplied by gear reduction mechanism i.e. pulley belt and spur gear with pinion gear. Then after getting the required rpm the appropriate electric generator will be select and electric power will produce.

\subsection{Cost Estimation and Feasibility Analysis}

Table 1: approximate cost estimation of reciprocating type wind power harvester parts

\begin{tabular}{|c|c|c|c|c|c|}
\hline $\mathrm{S} / \mathrm{N}$ & Part name & Quantity & Material & Manufacturing process & $\begin{array}{l}\text { Estimation } \\
\text { cost(birr) }\end{array}$ \\
\hline 1 & Generator & 1 & & $\begin{array}{l}\text { Purchase according to } \\
\text { specification }\end{array}$ & 40,000 \\
\hline 2 & Flat belt & 1 & oak leather & purchase & 300 \\
\hline 3 & Pulley & 1 & cast iron & sand mold casting & 200 \\
\hline 4 & Shaft & 2 & cold drown 1020 steel & Machining (by lathe machine) & 450 \\
\hline 5 & Ball bearing & 2 & - & purchase & 150 each \\
\hline 6 & Tower & 1 & $\begin{array}{l}\text { Steel aisi } 1045,5 \mathrm{~m} \\
\text { long hollow circular } \\
\text { cross-section }\end{array}$ & $\begin{array}{l}\text { Machining and welding } \\
\text { according to dimension }\end{array}$ & 4060 \\
\hline 7 & Pin & 3 & Steel & Machining (milling machine) & 200 \\
\hline 8 & Key & 3 & Steel & Machining by lathe machine & 200 \\
\hline 9 & Bolt & 4 & Steel & $\begin{array}{l}\text { Purchasing according to } \\
\text { dimension }\end{array}$ & 500 \\
\hline 10 & Frame & 1 & $\begin{array}{l}\text { Aluminum using } 9 \mathrm{~m} \\
\text { long hollow circular } \\
\text { cross section }\end{array}$ & $\begin{array}{l}\text { Cutting and welding } \\
\text { according to dimension (MIG } \\
\text { welding) }\end{array}$ & $\begin{array}{l}\text { 700birr per } \\
\text { meter }\end{array}$ \\
\hline 11 & Module & 3 & $\begin{array}{l}\text { Sheet metal } 5 \mathrm{~m} 2 \& 30 \\
\mathrm{~m} \text { aluminum hollow c/S }\end{array}$ & $\begin{array}{l}\text { Cutting \& welding with its } \\
\text { dimension (MIG welding) }\end{array}$ & 2500 \\
\hline 12 & Flywheel & 1 & Cast iron & Sand mold casting & 600 \\
\hline 13 & $\begin{array}{l}\text { Connecting } \\
\text { rod }\end{array}$ & 2 & $\begin{array}{l}\text { Steel its } \mathrm{c} / \mathrm{s} \text { is } \\
\text { rectangular }\end{array}$ & $\begin{array}{l}\text { cutting according to } \\
\text { dimension }\end{array}$ & 2000 \\
\hline 14 & Spring & 1 & steel & purchase & 700 \\
\hline 15 & $\begin{array}{l}\text { Cam and } \\
\text { follower }\end{array}$ & 1 & $\begin{array}{l}\text { steel and its cross } \\
\text { section are circular } \\
\text { solid }\end{array}$ & $\begin{array}{l}\text { machine on lathe, milling and } \\
\text { drilling }\end{array}$ & 800 \\
\hline 16 & Rope & 1 & $\begin{array}{l}\text { steel wire \& its Lis } \\
3.5 \mathrm{~m} \text { long }\end{array}$ & Purchase & 1200 \\
\hline 17 & Spur gear & 2 & cast & machine on milling & 1000 \\
\hline \multicolumn{5}{|c|}{ Total cost } & 66,010 \\
\hline
\end{tabular}

In this cost estimation there are some components which quantity is not specified or described above and there may be additional components that are required to accomplish our design project like Cam and follower, key, pin, bolt and others.so by considering all those components we would design our project with total initial investment cost of which does not exceed 150,000 Ethiopian Birr or \$5357.14

\section{CONCLUSSION}

Wind energy has been a reasonably successful renewable energy technology developed and widely distributed in the world. it also reduces the green house emission, reduce the demand of wood and charcoal for cooking therefore it helps us to preserve forested areas indirectly when all the cooking methods replaced by electricity power.so this project will play a vital role for increasing the supply of electric power in developing countries like Ethiopia due to its low manufacturing and maintenance cost.

The capacity of this reciprocating type wind power harvest is depending on the wind speed and area of the rectangular plate so in this design at a given area of rectangular plate in a. specified altitude it produces the ideal output power of $10.125 \mathrm{kw}$, So this output power will used for many minimum power consuming purposes like television, cooking foods, light etc. We can also increase the capacity of this machine by increasing the area of the plate and height of the wind harvester.

The output power of 10125 watt produced by the maximum wind speed can operate 56.25 lamps per day for 
three hours i.e. the consumption of each lamp is $60 \mathrm{~W}$. And its capacity will be increased by increasing the tower height.

\section{REFERENCE}

[1] J. F. Manwell and J. G. Mc Gowan Wind Energy Explained Theory, Design and Application Second Edition

[2] R.S. Khurmie And J.K. Gupta, a Textbook Of machine design by, 2005

[3]. David H. and Myszka, Machines and Mechanisms, Applied Kinematic Analysis, Fourth Edition by University of Dayton

[4]. Verónica Cabanillas, "Studied Blade Performance Analysis and Design Improvement of A Small Wind Turbine for Rural Areas", University of Purdue West Lafayette, August 2013

[5]. Peter J. Schubel and Richard J. Crossley, "Wind Turbine Blade Design, Nottingham UK, April 2012.

[6]. Ravi Anant Kishore, "Small-scale Wind Energy Portable Turbine (SWEPT)", May 06, 2013.

[7]. F.W. Perkins and D.E. Cromack, "Wind Turbine Blade Stress Analysis and Natural Frequencies", University of Massachusetts Amherst, Massachusetts 01003, August 1978.

[8]. Jean-Jacques chattot, "Design and analysis of wind turbines using helicoidally vortex model" California, December 9, 2001.

[9]. Salih Mohammed Salih, Mohammed Qasim etal, Performance analysis of wind turbine systems under different parameters effect, International Journal of Energy and Environment

10. S, Timoshenko Strength Of Materials Advanced Theory And Problems Second Edition 